\title{
Efecto de la Incorporación de Microcápsulas sobre Propiedades Mecánicas y de Barrera en Películas Binarias
}

\author{
Rafael E. González ${ }^{(1) \star}$, Arnulfo A. Tarón-Dunoyer ${ }^{(1)}$ y Omar F. Cuadro Mogollón ${ }^{(2)}$ \\ (1) Departamento de Operaciones Unitarias. Grupo de Investigación Biotecnología de Alimentos y \\ Educación (GIBAE). Universidad de Cartagena, Piedra de Bolívar - Av Del Consulado, Calle 30 № 48-157., \\ Cartagena D.T. y C., Colombia. (e-mail: rgonzalezc1@unicartagena.edu.co) \\ (2) Corporación Universitaria del Huila, Corhuila, Facultad de Ingenierías, Ingeniería Ambiental Calle 8 № \\ 32-49 Huila, Colombia.
}

Recibido Oct. 5, 2017; Aceptado Nov. 27, 2017; Versión final Dic. 17, 2017, Publicado Jun. 2018

\begin{abstract}
Resumen
El objetivo del presente estudio fue evaluar el efecto de la incorporación de microcápsulas de tamaño controlado conteniendo bacterias probióticas (Lactobacillus casei y Lactobacillus acidophilus) sobre las propiedades mecánicas y de barrera de películas a base de gelana de alto acilo y alginato de sodio. Las microcápsulas fueron elaboradas por el método de gelación iónica, mientras que las películas por el método de casting. Las microcápsulas modificaron las propiedades mecánicas y de barrera de las películas analizadas. Sin embargo, cuando las microcápsulas fueron cargadas con bacterias probióticas no se presentó una variación significativa $(p>0.05)$ en comparación con aquellas películas que contenían microcápsulas sin carga probiótica. Estos resultados abren la posibilidad de diseñar películas conteniendo como principio activo bacterias probióticas sin ocasionar alteraciones significativas en las películas atribuibles al crecimiento probiótico. Por tanto, se puede sugerir la posibilidad de utilizar estos materiales para la obtención de empaques activos en aplicaciones alimentarias.
\end{abstract}

Palabras clave: elongación al quiebre; goma gelana; permeabilidad al vapor de agua; películas; resistencia a la tensión; transparencia

\section{Effect of Microcapsules Incorporation on the Mechanical and Barrier Properties of Binary Films:}

\begin{abstract}
The objective of the present study was to evaluate the effect of the incorporation of size-controlled microcapsules containing probiotic bacteria (Lactobacillus casei and Lactobacillus acidophilus) on the mechanical and barrier properties from films based on high acyl gellan and sodium alginate. The microcapsules were made by the internal ionic gelation method, while the films by the casting method. The findings showed that microcapsules modified the mechanical and barrier properties of the analyzed films. However, when the microcapsules were loaded with probiotic bacteria there was no significant variation ( $p>$ 0.05 ) compared to those films without probiotic load, these results are interesting because open the possibility of designing films containing probiotic bacteria as an active principle without causing significant alterations in films that being due to probiotic growth. Therefore, it is possible to suggest the possibility of using these materials to obtain active packages for food applications.
\end{abstract}




\section{INTRODUCCIÓN}

Los consumidores demandan mayor calidad y vida útil en los productos alimenticios, así como una disminución en el uso de materiales termoplásticos, los cuales presentan problemas de biodegradabilidad en el medio ambiente (Sorrentino et al., 2007). Tales demandas han ocasionado una creciente interés en el desarrollo de películas y materiales biodegradables que tengan la capacidad de incrementar la calidad de cualquier sistema alimentario (Jongjareonrak et al., 2006). Con el propósito de proteger los productos alimenticios contra el oxígeno, dióxido de carbono, lípidos, aromas, sabores y humedad se han utilizado películas poliméricas biodegradables como sustitutos de los tradicionales empaques plásticos (Cao et al., 2009). Las fuentes más comunes para la obtención de películas biodegradables son biopolímeros, tales como proteínas, lípidos y polisacáridos, entre otros (Pereda et al., 2011; Al-Hassan y Norziah, 2012).

Películas a base de materiales biopoliméricos han sido estudiadas; ya que estos materiales son considerados amigables con el medio ambiente, además presentan algunas propiedades que pueden ser interesantes en la preservación de productos alimenticios (Abdollahi et al., 2012). Sin embargo, la principal desventaja que enfrentan este tipo de películas son su débiles propiedades mecánicas y de barrera, las cuales limitan su rango de aplicaciones en diversas matrices alimentarias, por ejemplo en aquellos alimentos con elevado contenido de agua o aquellos que necesiten un almacenamiento en ambientes húmedos (Yang et al., 2009). Por tal motivo, varias estrategias han sido utilizadas con el fin de incrementar las propiedades mecánicas y de barrera como el mezclado de polímeros sintéticos o naturales (Wang et al., 2010), de compuestos hidrofóbicos (Olivas y Barbosa, 2008) y el reforzamiento del gel por entrecruzamiento (González et al., 2017).

Entre los biopolímeros utilizados para el desarrollo de películas se encuentran: la goma gelana y el alginato. El alginato de sodio es un polímero natural extraído de algas marinas compuesto principalmente de enlaces (1-4) de unidades $\beta$-D- de ácido manúronico y $\alpha$-L gulurónico, además contiene grupos carboxilo que le confieren diversas habilidades gelificantes para ser utilizado como un material funcional (Artiga et al., 2017), dentro de sus propiedades más atractivas para ser utilizado en el diseño de películas biodegradables, se encuentran su inocuidad, buena biocompatibilidad y biodegradabilidad, lo cual ha conllevado a su aplicación en diversas campos, como el alimentario en la producción de películas para incrementar la vida útil de productos alimenticios (González et al., 2016), la producción de cargadores biológicos o enzimáticos y la ingeniería de materiales, entre otros (Yang et al., 2009). La goma gelana es un polímero lineal aniónico productor de geles constituido de monosacáridos de $\beta$-1,3-D-glucosa, $\beta-1,4-D$ ácido glucurónico y $\alpha-1,4-\mathrm{L}-$ ramnosa en radios molares de 2:1:1. La gelana nativa es conocida como gelana de alto acilo y tiene una sustitución del grupo glicerato C2 y acetato C6 localizados en el residuo de glucosa A en un $50 \%$ (Bradbeer et al., 2014). Tanto la goma gelana como el alginato de sodio han sido recomendados como una adecuada matriz encapsulante o material pared de bacterias probióticas debido a que producen microcápsulas esféricas e incrementan la viabilidad de bacterias probióticas (González et al., 2015), lo cual puede ser de gran utilidad al momento de producir empaques activos. Un empaque activo es aquel que posee una sustancia en su interior que le permita incrementar la vida útil de los productos alimenticios (Ghaani et al., 2016). Sin embargo, muchos de las sustancias antimicrobianas incorporadas son liberadas rápidamente al exterior. En tanto, autores han fijado los principios activos en microcápsulas con el fin de liberarlos gradualmente y así tener un efecto antimicrobiano sostenido en el tiempo incrementando la vida útil del alimento recubierto (González et al., 2016).

La microencapsulación es un proceso mediante el cual ciertas sustancias bioactivas son retenidas dentro de una matriz o sistema pared con el fin de protegerlas de condiciones ambientales deletéreas, prevenir pérdidas y liberarlas gradualmente bajo condiciones controladas (González et al., 2013). La gelación iónica es una técnica sencilla, rápida y de bajo costo utilizada para microencapsular células (Ibarguren et al., 2012). En tal sentido resulta de gran interés incorporar microcápsulas en películas con el fin de liberar gradual y sostenidamente el contenido de las mismas sobre el producto en el que son aplicadas. En el presente trabajo el principio activo a microencapsular son bacterias probióticas del género Lactobacillus $s p$ debido a que son tradicionalmente utilizadas en la elaboración de productos fermentados y proporcionan efectos benéficos a los consumidores potenciales (González et al., 2014).

Hasta la fecha, no hay información concerniente al efecto que ocasiona la incorporación de microcápsulas sobre propiedades mecánicas y de barrera de las películas. Dentro de las propiedades mecánicas, las de mayor relevancia en la selección de materiales de cobertura son la resistencia a la tensión (RT) y la elongación al quiebre $(E Q)$ porque proporcionan una idea de la resistencia y versatilidad del material a utilizar como recubrimiento (Kurt y Kahyaoglu, 2014). Por todo lo mencionado anteriormente, el objetivo del presente estudio fue evaluar el efecto de la incorporación de microcápsulas de tamaño controlado cargadas de bacterias probióticas sobre la RT, EQ además de otras propiedades de importancia como la permeabilidad al vapor de agua de películas binarias. 


\section{MATERIALES Y MÉTODOS}

El alginato de sodio (SA), la goma gelana de alto (GAA) y bajo acilo (GBA) así como la glucono $\delta$ lactona de grado alimenticio fueron obtenidas de Modernish pantry (EEUU). El $\mathrm{CaCO}_{3}$ y el glicerol fueron suministrados por Merck-Colombia. Las bacterias probióticas fueron adquiridas en el Laboratorio de Microbiología de Alimentos de la Universidad de Cartagena-Colombia.

\section{Microencapsulación}

Inicialmente se prepararon dispersiones poliméricas de gelana de bajo acilo (GBA) al 0,5\% (p/v) en agua destilada. Después $\mathrm{CaCO}_{3}$ fue adicionado a cada preparación anterior en una concentración final de calcio de $30 \mathrm{mM}$. Posteriormente, se llevó a cabo una agitación constante en una plancha de calentamiento (Thermolyne nuova II) a una temperatura de $90^{\circ} \mathrm{C}$ durante 10 minutos. Finalmente, las dispersiones se dejaron enfriar y se agregó una concentración de bacterias probióticas (Lactobacillus casei y Lactobacillus acidophilus) a una concentración de $8 \log 10 \mathrm{UFC} / \mathrm{mL}$. A partir de estas dispersiones se llevó a cabo la microencapsulación de las bacterias probióticas por medio de la técnica de gelación iónica interna, en la cual las dispersiones conteniendo las bacterias probióticas fueron adicionadas en aceite vegetal de girasol en una relación (1:2 v/v dispersión/aceite) bajo agitación constante. Seguidamente, fue adicionada $\delta$-gluconolactona hasta alcanzar un $\mathrm{pH} 4$ con el fin de iniciar el proceso de gelificación, al liberar los iones de calcio del carbonato. Finalmente, las microcápsulas formadas fueron lavadas y centrifugadas (4000 rpm) tres veces en solución salina estéril para luego determinar por microscopia óptica que los diámetros de las microcápsulas se encuentren entre 15 y $80 \mu \mathrm{m}$.

\section{Elaboración de las películas binarias}

Las soluciones para la formación de películas se obtuvieron a partir de dispersiones de gelana de alto acilo (GAA) y alginato de sodio (SA) y sus mezclas así: 25GAA/75SA, 50GAA/50SA y 75GAA/25SA al 5,0 \% (p/v) disueltas en agua desionizada conteniendo $30 \mathrm{mM}$ de calcio. Subsecuentemente, cada dispersión preparada fue adicionada con $12 \%(\mathrm{v} / \mathrm{v})$ de glicerol como agente plastificante a cada preparación. Después, las soluciones fueron sometidas a $90^{\circ} \mathrm{C}$ por 20 minutos en baño termostatado bajo agitación constante. Para la formación de las películas se dejaron enfriar las preparaciones y las microcápsulas fueron agregadas $(1 \mathrm{~g})$ para finalmente verter volúmenes específicos en cajas de Petri. El secado se realizó en incubadora a $30^{\circ} \mathrm{C}$ durante 45 horas asegurando uniformidad de las películas. Películas control de cada dispersión fueron preparadas así: películas con microcápsulas vacías (sin bacteria probiótica) y películas sin microcápsulas. Todas las películas fueron aclimatadas durante $2 \mathrm{~h}$ antes de realizar el análisis respectivo.

\section{Propiedades mecánicas}

La RT y la EQ fueron determinadas con ayuda de un texturometro Shimadzu modelo EZ-Test EZ-S. Muestras de $3 \times 6 \mathrm{~cm}$ fueron fijadas en la parte superior e inferior utilizando una geometría de mordazas. La velocidad de separación de las mordazas fue de $30 \mathrm{~mm} / \mathrm{min}$. Los valores de RT fueron calculados dividiendo la carga máxima $(\mathrm{N})$ por el área transversal $\left(\mathrm{m}^{2}\right)$ de las películas (Ecuación 1).

$\mathrm{RT}(\mathrm{MPa})=\frac{\mathrm{Fmax}}{\mathrm{A}}$

Donde Fmax es la máxima fuerza necesaria para romper la muestra $(\mathrm{N})$ y $\mathrm{A}$ corresponde al área transversal de las BP $\left(\mathrm{m}^{2}\right)$ que es estimada al multiplicar el ancho por el espesor de la muestra. Con respecto a EQ, la ecuación 2 fue utilizada para su estimación.

$\mathrm{EQ}=\frac{\mathrm{l}_{\max }}{\mathrm{l}_{\mathrm{o}}} \times 100$

Donde $I_{\max }$ es la elongación $(\mathrm{mm})$ al momento de la rotura; y lo es longitud inicial $(\mathrm{mm})$. Todas las determinaciones fueron realizadas diez veces reportando los promedios aritméticos con sus respectivas desviaciones estándar (Nur Hazirah et al., 2016; González et al., 2017).

\section{Espesor, contenido de humedad y absorción de luz de las películas}

El espesor de las películas fue determinado por medio de un micrómetro con una exactitud de 0,01 $\mathrm{mm}$. Seis diferentes sitios de las películas fueron medidos reportando el promedio aritmético y sus desviaciones estándar. El contenido de humedad fue calculado tres veces por gravimetría (secado de las muestras durante $105^{\circ} \mathrm{C} / 24 \mathrm{~h}$ ) reportando los promedios aritméticos. Las propiedades de barrera a la luz fueron determinadas 
tres veces a cada película por exposición de estas a adsorción de luz a $560 \mathrm{~nm}$. Muestras rectangulares de las películas $(2 \times 3 \mathrm{~cm})$ fueron colocados en una celda de un espectrofotómetro (Thomson Gold Spectrumlab 54). La transparencia se estableció mediante la siguiente ecuación:

$\operatorname{Tr}=A 560 / \mathrm{x}$

Donde, A560 es la absorbancia a $560 \mathrm{~nm}$ y x es el espesor de las BP $(\mathrm{mm})$. El mayor valor de transparencia representa la menor transparencia en las BP.

\section{Permeabilidad del vapor de agua (PVA)}

Esta propiedad se estimó conforme al método descrito por la ASTM E96 (ASTM, 2010). Celdas de vidrio con diámetros de $4,5 \mathrm{~cm}$ y alturas de $3,0 \mathrm{~cm}$ fueron utilizadas. Estas celdas conteniendo $25 \mathrm{~g}$ de silica gel $(0 \% \mathrm{HR})$ fueron secadas en horno a $120^{\circ} \mathrm{C}$ durante $24 \mathrm{~h}$ y el espacio de cabeza para cada celda fue de $1,0 \mathrm{~cm}$ desde la abertura de cada celda. Las películas fueron selladas en la parte superior de cada celda. Cada montaje fue colocado en un desecador conteniendo agua destilada $(100 \mathrm{HR})$ y almacenado a $30^{\circ} \mathrm{C}$. Las celdas fueron pesadas con intervalos de $24 \mathrm{~h}$ durante una semana. Finalmente los pesos fueron graficados como una función del tiempo y la pendiente de cada línea es calculada por regresión lineal $\left(R^{2}>0,99\right)$. La determinación de la PVA fue estimada tres veces para cada película partir de la siguiente formula:

$P V A=(V T V A L) / \Delta P$

Donde VTVA es la velocidad de transmisión del vapor de agua $\left(\mathrm{gm}^{-2} \mathrm{~h}^{-1}\right)$ través de la película, calculada de la pendiente de la línea recta dividida por el área de la película expuesta $\left(\mathrm{m}^{2}\right)$, $L$ es el espesor de la película (mm) y $\Delta \mathrm{P}$ es la diferencia de la presión parcial del agua a través de los dos lados de la película.

\section{Análisis de Datos}

El programa de computo SPSS (Statistical Package for the Social Sciences) versión 17,0 fue utilizado en este estudio con el fin de analizar los datos. Análisis normal de varianza (ANOVA - un factor) fue llevado a cabo usando la prueba de tukey con un nivel de confianza del $95 \%$.

\section{RESULTADOS Y DISCUSIÓN}

Para una mejor organización, los resultados y su discusión se presentan en dos secciones: (i) RT y EQ; y (ii) Espesor, contenido de humedad, transparencia y PVA de las películas

\section{Propiedades mecánicas}

Es importante destacar que las microcápsulas incorporadas en las películas presentaron un comportamiento unimodal con diámetros entre 15 y $80 \mu \mathrm{m}$. Este comportamiento puede ser explicado a causa de la lenta liberación de los iones de calcio del carbonato de calcio debido a la lenta disrupción de la $\delta$-gluconolactona (Peláez y Karel, 1981; González et al., 2013). Los mayores valores de RT (45,34 MPa) se encontraron en películas a base de SA; lo cual puede ser atribuido a la formación de múltiples enlaces iónicos entre cadenas de alginato con carga negativa y los iones de calcio liberados por la $\delta$-gluconolactona (Panouillé y Larreta, 2009). La presencia de microcápsulas con y sin microorganismos probióticos disminuyó significativamente $(p<0,05)$ la RT de películas a base de SA hasta 37,67 y 38,88 MPa respectivamente. Por el contrario, películas a base de GAA conteniendo microcápsulas tuvieron los menores valores de RT (12,33 a 12,76 MPa) y no se observaron diferencias $(p>0,05)$ respecto a la presencia 0 ausencia de bacterias probióticas. Igualmente, películas de GAA sin microcápsulas tuvieron valores de 23,37 MPa. Los bajos valores encontrados en las películas de GAA puede ser consecuencia de la formación de impedimentos estéricos ocasionados por la presencia de grupos acilos que impiden la formación de enlaces iónicos entre las hélices de GAA (González et al., 2013). Las películas elaboradas con las distintas mezclas GAA/SA presentaron valores intermedios (18,00 a 40,77 MPa) entre los valores reportados para aquellas películas obtenidas con GAA y SA individualmente.

La proporción de SA en las películas es directamente proporcional a los valores de RT obtenidos; ya que al incrementar la concentración de SA incrementa la RT (Figura 1). Es importante destacar que la presencia de microorganismos no afectó significativamente $(p>0,05)$ los valores de RT; sin embargo, la presencia de microcápsulas disminuye la RT, por lo que las películas control siempre presentan mayores valores de RT que aquellas que contienen microcápsulas. Este comportamiento puede ser consecuencia de la obstaculización por parte de las microcápsulas de la interacción entre los grupos carboxilo e hidroxilo presentes, lo cual pudo ocasionar una disminución en el número de enlaces establecidos entre las cadenas 
poliméricas de GAA y el SA. En términos generales, la RT fue afectada en primer lugar por la proporción del polímero (GAA y SA) utilizada, seguida de presencia o ausencia de microcápsulas, mientras que la incorporación de bacterias probióticas en las microcápsulas no tuvo ningún efecto en esta propiedad.

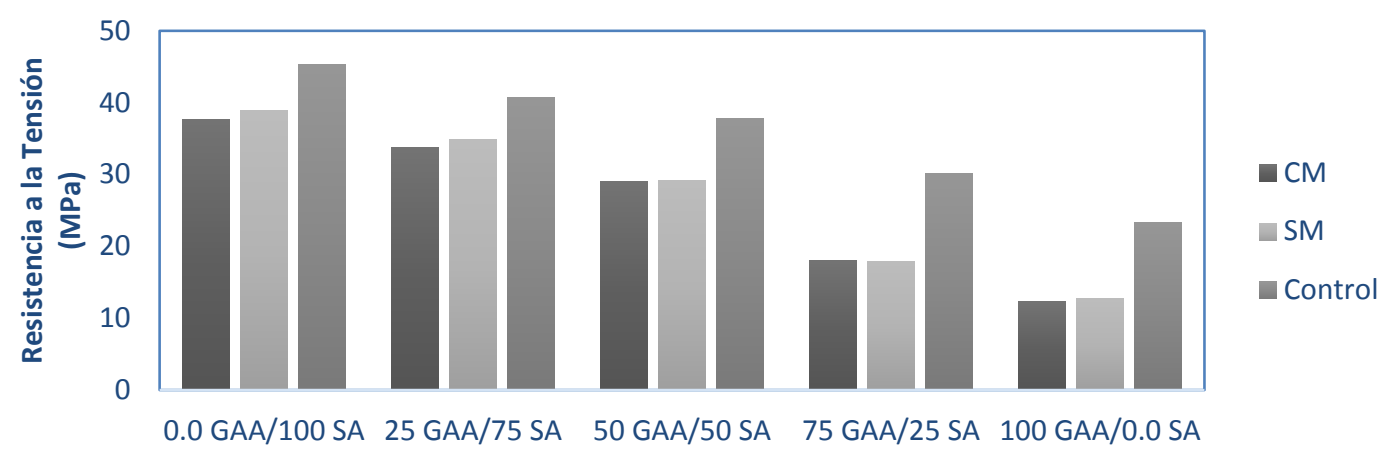

Fig. 1: Valores de Resistencia a la tensión en biopelículas binarias conteniendo microcápsulas

Con respecto a la EQ, se puede apreciar en la Figura 2 que los mayores valores fueron obtenidos en películas control a base de GAA con 6,98 \%, seguido por las películas de GAA con microcápsulas vacías (6,73\%) y microcápsulas conteniendo las bacterias probióticas con 6,69\%; mientras que los menores porcentajes de EQ se encontraron en películas a base de SA con microcápsulas cargadas con bacterias probióticas con 0,45 $\%$ y microcápsulas vacías con $0,51 \%$. Películas control de SA $(1,18 \%)$ tuvieron un aumento significativo $(p<0.05)$ en el porcentaje de EQ. Las películas elaboradas con las diferentes mezclas de GAA/SA presentaron valores comprendidos entre 1,06 y 6,03 en donde se observó un marcado efecto de las proporciones de GAA y SA utilizadas, así como por la presencia de microcápsulas; ya que todas las películas elaboradas con microcápsulas presentaron una disminución significativa $(p<0,05)$ en los valores de $E Q$ en comparación a las películas control. Igualmente, es de gran relevancia destacar que también se presentaron diferencias significativas $(p<0,05)$ en los valores de $E Q$ al variar las proporciones de GAA y SA notándose un comportamiento directamente proporcional entre las concentraciones de GAA y la EQ. Normalmente, una disminución de la EQ puede ser ocasionada por la reducción de la movilidad en los segmentos de las cadenas poliméricas (Benavides et al., 2012; Davidovich y Bianco, 2010). En términos generales la GAA incrementó la EQ debido a su estructura que contribuyó en la formación de enlaces de hidrógeno, mientras que el SA incrementó la RT por la formación de enlaces iónicos vía iones de calcio que unen cadenas de alginato.

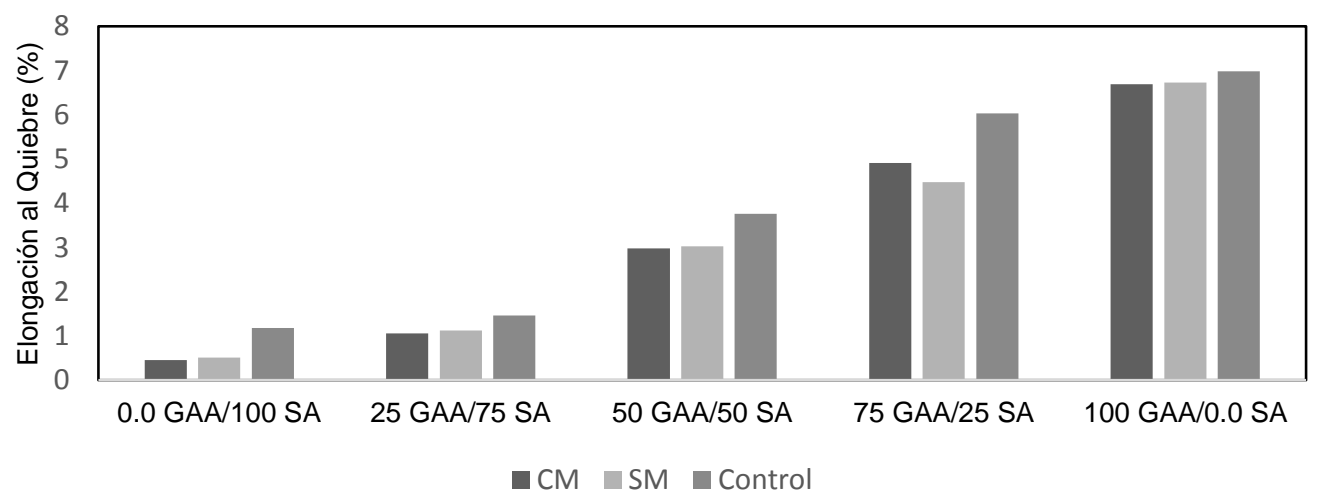

Fig. 2: Valores de elongación al quiebre en películas binarias conteniendo microcápsulas

\section{Espesor, contenido de humedad, transparencia y PVA de las biopelículas}

El espesor de las películas fue estrictamente controlado durante el proceso de elaboración, debido a que este parámetro afecta las propiedades mecánicas y de barrera (Liling et al., 2016), tales propiedades fueron evaluadas en el presente estudio. En tal sentido, no se encontraron diferencias significativas $(p>0,05)$ entre los espesores de distintas películas elaboradas, además, las microcápsulas incorporadas al presentar pequeños diámetros no afectaron el espesor de las películas. Los espesores encontrados van desde 0,10 a $0,11 \mathrm{~mm}$ y permiten según la Sociedad Americana para el ensayo de Materiales (ASTM por sus siglas en inglés) (ASTM D883-00 Actualizada en 2017) clasificarlas como películas, ya que tienen espesores inferiores a $0,12 \mathrm{~mm}$. 
Las películas con mayor contenido de humedad fueron aquellas elaboradas a base de GAA conteniendo microcápsulas vacías (33,17\%) y/o cargadas con las bacterias probióticas $(32,93 \%)$ (Tabla 1) y las películas control de GAA presentaron menores valores de humedad (28,76\%), este comportamiento puede ser atribuido a la naturaleza hidrofílica de la GAA, pero particularmente a la presencia de microcápsulas, un comportamiento similar fue reportado por Salazar et al., (2018) en donde encontraron que la presencia de microcápsulas modificó parámetros como la humedad en los alimentos en los cuales se incorporan. Por otro lado, menores valores de humedad (4,51\%) se encontraron en las películas control a base de SA seguidas de aquellas que contenían microcápsulas vacías $(6,11 \%)$ y cargadas con las bacterias probióticas (5,87 \%); es decir, la presencia de microcápsulas influyó sobre el contenido de humedad de las películas, mas no la presencia del microorganismo, ya que no se obtuvieron diferencias significativas ( $p>0,05)$ en las películas conteniendo microcápsulas con y sin carga probiótica, este resultado reveló que la bacteria utilizada no tuvo el tiempo suficiente para multiplicarse y utilizar el agua disponible. Comportamientos similares fueron observados en las películas obtenidas con mezclas de GAA y SA. En tal sentido se puede decir que la GAA tuvo mayor afinidad con moléculas de agua que el SA y que la presencia de microcápsulas puede atrapar en su interior moléculas de agua incrementando los valores de humedad en las películas. El mayor contenido de humedad en las películas de GAA con microcápsulas, puede ser consecuencia de un aumento en el número de enlaces formados en la gelana, aunque no se debe descartar la mayor disponibilidad de grupos hidroxilo disponibles para interactuar con moléculas de agua, tal comportamiento también fue reportado por Martins et al., (2012) en películas binarias compuestas por k - carragenato y goma algarrobo.

Como se puede apreciar en la tabla 1, la presencia de microcápsulas afectó significativamente $(p<0,05)$ los valores de transparencia de las películas. La transparencia es una cualidad deseada para el empacado de algunas matrices alimentarias porque afecta la apariencia final del producto alimenticio y determina la aplicación final del recubrimiento, en tal sentido, las películas con mayor transparencia fueron aquellas elaboradas a partir de GAA sin la presencia de microcápsulas con un valor de 1,47, seguida por las mezcla 75GAA/25SA de las películas control con 1,71. Por el contrario, las películas menos transparentes fueron aquellas a base de SA que contenían microcápsulas con y sin bacterias probióticas con índices de transparencia de 3,38 y 3,41 respectivamente. Los mayores valores de transparencia indican menores valores de absorbancia (Dick et al., 2015). Yang et al., (2010) atribuyen que el incremento en la opacidad de las películas comestibles es una consecuencia de una disminución del espacio entre cadenas poliméricas lo cual conduce a un menor paso de la luz a través del material de cobertura. Aunque una mayor absorción de la luz por parte de las películas puede ser también una excelente barrera y prevenir la oxidación lipídica inducida por la luz cuando es aplicada en un sistema alimentario (Gómez et al., 2007). Los índices de transparencia que en este trabajo se reportan son menores a los publicados por Nur Hazirah et al., (2016) en películas a base de carboximetilcelulosa y gelatina, estos autores reportaron índices de 1,99, lo cual indica que la GAA y el SA producen películas menos transparentes y al adicionar microcápsulas la transparencia disminuye significativamente $(p<0,05)$. Es notable destacar que en esta propiedad se sigue el patrón observado previamente, en donde la presencia de las bacterias probióticas no tuvo ningún efecto significativo sobre la propiedad evaluada.

La PVA de agua es una propiedad de gran importancia y permite seleccionar los materiales adecuados para recubrir distintas matrices alimentarias, aunque no hay un valor exacto de PVA que haya sido reportado previamente como ideal para diversas matrices, es aceptado generalmente que la PVA debe tender a cero en aras de imitar los valores de los materiales termoplásticos y así disminuir la interacción del producto alimenticio con el medio circundante (Kurt y Kahyaoglu, 2014). Considerando lo anteriormente mencionado, el valor destacado de PVA se encontró en las películas control a base de SA con 14,72 $\mathrm{g} \mathrm{mm} / \mathrm{m}^{2} \mathrm{~d} \mathrm{kPa}$, este valor se incrementa hasta 18,44 y $18,65 \mathrm{~g} \mathrm{~mm} / \mathrm{m}^{2} \mathrm{~d} \mathrm{kPa}$ cuando se adicionan microcápsulas cargadas con las bacterias probióticas y microcápsulas vacías respectivamente. Los mayores valores de PVA 43,40 g mm/ $\mathrm{m}^{2} \mathrm{~d} \mathrm{kPa}$ y $42.99 \mathrm{~g} \mathrm{~mm} / \mathrm{m}^{2} \mathrm{~d} \mathrm{kPa}$ fueron obtenidos en las películas de GAA conteniendo microcápsulas con y sin carga probiótica en su interior. Tal comportamiento puede ser ocasionado por la influencia que ejercen las reacciones de entrecruzamiento sobre el coeficiente de difusión de humedad dentro de la red polimérica indicando cambios estructurales en la matriz polimérica.

De forma general, se aprecia que la PVA aumentó al incrementar el contenido de GAA, lo cual puede ser atribuido a la mayor cantidad de agua retenida al interior de la película que a su vez es consecuencia del mayor número de enlaces que establece la GAA para darle mayor estabilidad al gel que forma. Tal premisa es soportada por los resultados del contenido humedad previamente discutidos. La PVA es un indicador de como la humedad atraviesa las películas y es relacionado con las reacciones que deterioran la textura de las matrices alimentarias (Ahmadi et al., 2012). Es de gran relevancia aclarar que un incremento en la PVA permite el movimiento de vapor de agua a través de la película y tal movimiento de vapor en algunos casos puede ser importante con el fin de evitar los procesos de condensación dentro del empaque. Sin embargo, también puede promover procesos de crecimiento de hongos al interior del empaque afectando al alimento. Los resultados de PVA obtenidos en el presente estudio fueron mayores que películas sintéticas, tales como polietileno de alta densidad (PEAD) (0,0288 g mm/kPa d m2) y poliéster (0,02184 g mm/kPa d m2) (McHugh et al., 1993). 
Tabla 1. Espesor, contenido de humedad, PVA y valores de transparencia de BP, conteniendo microcápsulas. En la Tabla, $\mathrm{CM}=$ bacterias probióticas; $\mathrm{SM}=\sin$ bacterias probióticas. Las columnas sin ninguna letra en común presentaron diferencias significativas a un nivel de confianza del 95\%

\begin{tabular}{|c|c|c|c|c|}
\hline $\begin{array}{c}\text { Proporción de } \\
\text { GAA/SA }(\mathrm{p} / \mathrm{v})\end{array}$ & $\begin{array}{c}\text { Adición } \\
\text { microcápsulas }\end{array}$ & $\begin{array}{c}\text { Contenido de } \\
\text { humedad (\%) }\end{array}$ & $\begin{array}{c}\text { Transparencia } \\
\text { a 560 nm }\end{array}$ & $\begin{array}{c}\text { PVA (g mm/ } \\
\left.\mathrm{m}^{2} \mathrm{~d} \mathrm{kPa}\right)\end{array}$ \\
\hline $0 / 100$ & CM & $5.87 \pm 0,2^{\mathrm{a}}$ & $3.38 \pm 0.2^{\mathrm{a}}$ & $18.44 \pm 0.5^{\mathrm{a}}$ \\
\hline $0 / 100$ & SM & $6.11 \pm 0,1^{\mathrm{a}}$ & $3.41 \pm 0.4^{\mathrm{a}}$ & $18.65 \pm 0.4^{\mathrm{a}}$ \\
\hline $0 / 100$ & Control & $4,51 \pm 0,2^{\mathrm{b}}$ & $2,58 \pm 0,3^{\mathrm{b}}$ & $14,72 \pm 0,4^{\mathrm{b}}$ \\
\hline $25 / 75$ & CM & $12,18 \pm 0,2^{\mathrm{c}}$ & $2,93 \pm 0,1^{\mathrm{b}}$ & $20,46 \pm 0,7^{\mathrm{c}}$ \\
\hline $25 / 75$ & SM & $12,13 \pm 0,0^{\mathrm{c}}$ & $3,00 \pm 0,3^{\mathrm{cb}}$ & $21,20 \pm 1,1^{\mathrm{c}}$ \\
\hline $25 / 75$ & Control & $9,46 \pm 0,1^{\mathrm{d}}$ & $2,13 \pm 0,4^{\mathrm{c}}$ & $17,36 \pm 1,0^{\mathrm{d}}$ \\
\hline $50 / 50$ & CM & $18,84 \pm 0,1^{\mathrm{e}}$ & $2,63 \pm 0,1^{\mathrm{b}}$ & $22,88 \pm 0,8^{\mathrm{e}}$ \\
\hline $50 / 50$ & SM & $18,77 \pm 0,0^{\mathrm{e}}$ & $2,59 \pm 0,3^{\mathrm{b}}$ & $22,88 \pm 0,7^{\mathrm{e}}$ \\
\hline $50 / 50$ & Control & $11,06 \pm 0,2^{\mathrm{f}}$ & $1,94 \pm 0,3^{\mathrm{c}}$ & $17,74 \pm 0,5^{\mathrm{d}}$ \\
\hline $75 / 25$ & CM & $27,31 \pm 0,4^{\mathrm{g}}$ & $2,53 \pm 0,3^{\mathrm{b}}$ & $29,84 \pm 0,3^{\mathrm{e}}$ \\
\hline $75 / 25$ & SM & $28,49 \pm 0,3^{\mathrm{g}}$ & $2,48 \pm 0,1^{\mathrm{b}}$ & $30,06 \pm 1,7^{\mathrm{e}}$ \\
\hline $75 / 25$ & Control & $24,65 \pm 0,2^{\mathrm{h}}$ & $1,71 \pm 0,2^{\mathrm{c}}$ & $18,77 \pm 1,8^{\mathrm{b}}$ \\
\hline $100 / 0$ & CM & $32,93 \pm 0,3^{\mathrm{i}}$ & $2,18 \pm 0,3^{\mathrm{c}}$ & $43,40 \pm 1,4^{\mathrm{f}}$ \\
\hline $100 / 0$ & SM & $33,17 \pm 0,2^{\mathrm{i}}$ & $2,12 \pm 0,09^{\mathrm{c}}$ & $42,99 \pm 1,5^{\mathrm{f}}$ \\
\hline $100 / 0$ & Control & $28,76 \pm 0,3^{\mathrm{j}}$ & $1,47 \pm 0,23^{\mathrm{d}}$ & $35,74 \pm 1,2^{\mathrm{g}}$ \\
\hline
\end{tabular}

\section{CONCLUSIONES}

La goma gelana, el alginato de sodio y sus mezclas son agentes prometedores para la formación de matrices con inclusiones de microcápsulas y en un futuro cercano pueden potencialmente ser útiles en la producción de empaques activos biodegradables disminuyendo así contaminación ambiental. Las microcápsulas modificaron las propiedades físico mecánicas y de barrera de las películas analizadas. Sin embargo, cuando las microcápsulas fueron cargadas con bacterias probióticas no se presentó una variación significativa en las propiedades de las películas, lo cual abre la posibilidad de diseñar películas conteniendo como principio activo a bacterias probióticas sin ocasionar una alteración significativa en la película atribuible al crecimiento de la bacteria. Estos resultados sugieren la posibilidad de utilizar combinaciones de goma gelana/alginato y microcápsulas de tamaño controlado como una fuente de empaque biodegradable en aplicaciones alimentarias. No obstante, sería conveniente realizar en futuras investigaciones una caracterización de permeabilidad a gases como $\mathrm{O}_{2}$, dinámico-mecánica y térmica de estas películas con el fin de visualizar más claramente el potencial de aplicación de las películas dentro del sector alimentario.

\section{REFERENCIAS}

Abdollahi, M., M. Rezaei y G, Farzi, A novel active bionanocomposite film incorporating rosemary essential oil and nanoclay into chitosan, Journal of Food Engineering, 111, 343-350 (2012)

Ahmadi, R., Kalbasi, A. y otros tres autores, Development and characterization of a novel biodegradable edible film obtained from psyllium seed (Plantago ovata Forsk), Journal of Food Engineering, 109, 745-751 (2012)

Al-Hassan, A. y M. Norziah, Starch-gelatin edible films: water vapor permeability and mechanical properties as affected by plasticizers, Food Hydrocolloids, 26(1), 108-117 (2012)

American Society for Testing and Materials (ASTM), Standard terminology relating to plastic, Designation D883-00. Annual book of ASTM standards. Philadelphia, 13 (1985) actualized (2017).

American Society for Testing and Materials (ASTM E96), Standard Test Methods for Water Vapor Transmission of Materials, West Conshohocken: ASTM, 11 (2010)

Artiga, M., Acevedo, A. y O. Martín, Effect of sodium alginate incorporation procedure on the physicochemical properties of nanoemulsions, Food Hydrocolloids, 70, 191-200 (2017)

Benavides, S., R. Villalobos y J. Reyes, Physical, mechanical and antibacterial properties of alginate film: Effect of the crosslinking degree and oregano essential oil concentration, Journal of Food Engineering 110(2), 232-239 (2012)

Bradbeer, J. y otros tres autores, Self-structuring foods based on acid-sensitive low and high acyl mixed gellan systems to impact on satiety, Food Hydrocolloids, 35, 522-530 (2014)

Cao N., X. Yang y Y. Fu, Effects of various plasticizers on mechanical and water vapor barrier properties of gelatin films, Food Hydrocolloids, 23(3), 729-735 (2009) 
Davidovich, M. y H. Bianco, A quantitative analysis of alginate swelling, Carbohydrate Polymers, 79, 1020-1027 (2010)

Dick, M. y otros cinco autores, Edible film production from chia seed mucilage: Effect of glycerol concentration on its physicochemical and mechanical properties, Carbohydrate Polymers, 130, 198-205 (2015)

Ghaani, M., Cozzolino, C.A., G. Castelli y S. Farris, An overview of the intelligent packaging technologies in the food sector, Trends in Food Science and Technology, 51, 1-11 (2016)

Gómez, M. y otros cuatro autores, Edible films made from tuna-fish gelatin with antioxidant extracts of two different murta ecotypes leaves (Ugni molinae Turcz), Food Hydrocolloid, 21, 1133-1143 (2007)

González R., J. Salazar y J. Pérez, Obtaining size-controlled microcapsules by ionic gelation with high and low acyl gellans containing Lactococcus lactis, Revista Colombiana de Biotecnologia, 15(2), 70-80 (2013)

González R., J. Pérez, L. Morón, Efecto de la Microencapsulación sobre las Propiedades Reológicas y Fisicoquímicas del Yogurt Blando, Información Tecnológica, 25(6), 45-56 (2014)

González R., N. Urbina y J. Pérez, Efecto de la Microencapsulación sobre la Viabilidad de Lactobacillus delbrueckii sometido a Jugos Gástricos Simulados, Información Tecnológica, 26(5),11-16 (2015)

González R., Y. Altamar e I. Castro, Obtención de Biopelículas conteniendo Extracto Acuoso de Eucalyptus camaldulensis y su Incidencia en la Vida Útil Microbiológica de Rodajas de Carica papaya L. Información Tecnológica, 27(2), 61-66 (2016)

González R., A. Tarón y F. Colpas, Incidencia de los lones Divalentes y Monovalentes en las Propiedades Físico Mecánicas y de Barrera en Biopelículas a Base de Goma Gelana, Información Tecnológica, 28(2), 67-74 (2017).

Ibarguren, C. y otros tres autores, Anti-Listeria monocytogenes activity of enterocins microencapsulated by ionic gelation, Food Hydrocolloids, 29(1), 21-26 (2012).

Jongjareonrak, A. y otros cuatro autores, Characterization of edible films from skin gelatin of brown stripe red snapper and big eye snapper, Food Hydrocolloid, 20(4), 492-501 (2006)

Kurt, A. y T. Kahyaoglu, Characterization of a new biodegradable edible film made from salep glucomannan, Carbohydrate Polymers, 104(0), 50-58 (2014)

Liling, G. y otros cinco autores, Effects of ionic crosslinking on physical and mechanical propertiesof alginate mulching films, Carbohydrate Polymers, 136, 259-265 (2016)

Martins, J. y otros cinco autores, Synergistic effects between k-carrageenan and locust bean gum on physicochemical properties of edible films made thereof, Food Hydrocolloids, 29, 280-289 (2012)

McHugh, T., Avena, R. y J. Krochta, Hydrophilic edible films: Modified procedure for water vapor permeability and explanation of thickness effects, Journal of Food Science, 58(4), 899-903 (1993)

Nur Hazirah, M., N. Isab y M. Sarbon, Effect of xanthan gum on the physical and mechanical properties of gelatincarboxymethyl cellulose film blends, Food Packaging and Shelf Life, 9, 55-63 (2016)

Olivas, G. y G. Barbosa, Alginate-calcium films: water vapor permeability and mechanical properties as affected by plasticizer and relative humidity, LWT e Food Science and Technology, 41(2), 359-366 (2008)

Panouillé, M. y V. Larreta, Gelation behavior of gelatin and alginate mixtures, Food Hydrocolloids, 23(4), 1074-1080 (2009)

Peláez C. y M. Karel, Improved method for preparation of fruit-simulating alginate gels, Journal of Food Processing and Preservation, 5(2): 63-81 (1981)

Pereda M. y otros cuatro autores, Chitosan-gelatin composites and bi-layer films with potential antimicrobial activity, Food Hydrocolloids, 25(5), 1372-1381 (2011)

Salazar J. y otros tres autores, Effect of free and microencapsulated Lactococcus lactis on composition and rheological properties of Manchego-type cheeses during ripening, Food Research International, 105, 59-64 (2018)

Sorrentino, A., G. Gorrasi y V. Vittoria, Potential perspectives of bionanocomposites for food packaging applications, Trends in Food Science \& Technology, 18, 84-95 (2007)

Wang, L., M. Auty y J. Kerry, Physical assessment of composite biodegradable films manufactured using whey protein isolate, gelatin and sodium alginate, Journal of Food Engineering, 96, 199-207 (2010)

Yang, L. y otros cuatro autores, Sodium alginate/ $\mathrm{Na}^{+}$-rectorite composite films: preparation, characterization, and properties, Journal of Applied Polymer Science, 114, 1235-1240 (2009)

Yang, L., A. Paulson y M. Nickerson, Mechanical and physical properties of calcium-treated gellan films, Food Research International, 43, 1439-1443 (2010) 